\title{
The Impact of Decentralization of Fire Protection on Fire Deaths in the US: A Cross-State Analysis
}

\author{
Dmitry Shishkin \\ Georgia Gwinnett College
}

In this paper, we offer an estimate of the effect of decentralization of fire protection service on fire deaths in the US, while using individual US states as points of observation. We assess the degree of decentralization in each state by the average size of its fire departments, which is the basic unit of fire protection service in the US. A number of other factors that are relevant to the causes of fires are included in our regression model. Our results show that the size of fire departments measured both in population and in the area served by one fire department positively correlates with fire death rate. We interpret these results as an evidence that there is room for improving efficiency in fire protection service around the US through decentralization.

Keywords: governmental decentralization, fire protection, local government

\section{INTRODUCTION}

Motivation for this work comes from noticing how much variation one can notice in the degree of decentralization in fire protection in the countries around the world. In some countries (for example, the Czech Republic) fire protection service is organized at national level, in some (for example, Australia) state governments run fire protection service, and in some (for example, the United States) fire protection is organized at local level. A quick look at the worldwide data on fire statistics also shows a great variation in those numbers as well. Thus, an intriguing question arises: to what extent the variation in fire statistics across different territories can be explained by variation in their characteristics, in particular by variation in the degree of decentralization of their fire protection services. We are focusing on the degree of decentralization rather than some other parameter as there is extensive research that shows that decentralization is capable of benefiting various sectors of publicly provided services. Moreover, on top of being an active area of academic research, decentralization has been attracting attention of many developed and developing countries over the last several decades as a path to achieving a more efficient public sector. We believe that if there is evidence that decentralization helps to improve provision of public education, health, and other important public services then it is probable that decentralization might also improve the efficiency of fire protection service provision.

While the initial inspiration for this work came from observing differences in the worldwide fire protection service data and fire losses statistics, in this work we choose to set our focus on only one country, namely the United States. The main reason for this decision is that the relevant data are more readily available in the US. We hope that the results received in this work would inspire further research on this topic using data sets that might be available for other countries or even using the data collected for various 
countries around the world. Another choice that we have to make due to the limitation of the data is relying on fire deaths as a proxy for the destructive effect of fires across the territories. Economic losses caused by fires would definitely be a useful parameter to use in addition to fire deaths, however this variable is only available as an aggregate for the entire nation, but not for each individual state.

\section{ECONOMIC EFFECT OF UNINTENDED FIRES}

Destructive fire takes a regular toll in lives, injuries, and economic losses: the net losses due to fire incidents in 2014 constitute 55.4 billion, which represents $0.32 \%$ of the U.S. Gross Domestic Product (Zhuang, Payyappalli, Behrendt, \& Lukasiewicz, 2017). "In 2019, local fire departments responded to an estimated 1.3 million fires. These fires caused roughly 3,700 civilian fire deaths and 16,600 reported civilian fire injuries. Property damage was estimated at $\$ 14.8$ billion (Ahrens \& Evarts, 2020). Even more money is spent every year to keep those losses at check: according to the same source, in $2014 \$ 273.1$ billion was spent in the U.S. for fire protection, which represents $1.58 \%$ of the U.S. GDP. That many casualties being lost and that much resources being spent in the field of fire protection calls for research aimed at better understanding underlying causes of destructive fires and finding potential improvements in efficiency when dealing with fire protection. While there are various specialized journals that focus on technological side of fire protection there are only limited attempts to address the issue from a broader socio-economic perspective.

\section{LITERATURE REVIEW}

The literature review covers the following topics relevant to our work: 1) theoretical and empirical evidence of beneficial effects from decentralization 2) the concept of decentralization and its various forms 3) measuring decentralization 4) identifying factors that can help explain variation in fire loss statistics between different territories.

\section{Theoretical and Empirical Evidence of Beneficial Effects From Decentralization}

Why should we expect any positive effects from decentralization on fire safety outcomes? The main theoretical argument that supports such expectations is the well-known Oates' decentralization theorem that states that in the presence of diverse preferences and needs, provision of public services by a decentralized government structure should lead to improved citizen welfare. On empirical ground, there is research that presents evidence of decentralization having the potential to improve certain aspects of public service delivery. Martinez-Vazquez et al. provide a survey of the impact of fiscal decentralization on the economy, society, and politics, citing a number of works that present such evidence (Martinez-Vazquez, Lago-Penas, $\&$ Sacchi, 2017). In particular, there is evidence that decentralization makes public investment in education and other services more responsive to local needs (Faguet, 2004), decreases infant mortality rates (Habibi, et al., 2003), helps student performance (Falch \& Fischer, 2012), improves enrollment rates in public schools and access of the poor to public health services (Faguet \& Sanchez, Decentralization and access to social services in Colombia., 2014), and is associated with lower natural disaster death rates (Escaleras \& Register, 2012). Also, Freinkman and Plekhanov report that fiscal decentralization has a significant positive effect on average examination results and the quality of municipal utilities provision in Russian regions (Freinkman \& Plekhanov, 2010).

\section{The Concept of Decentralization and Its Various Forms}

There are plenty of definitions of decentralization that can be found in the literature. For example, Rondinelli defines it as the transfer or delegation of legal and political authority to plan, make decisions and manage public functions from the central government and its agencies to the following entities: 1) field organizations of those agencies, 2) subordinate units of government, 3) semiautonomous public corporations, 4) areawide or regional development authorities; 5) functional authorities, 6) autonomous local governments, 7) nongovernmental organizations. (Rondinelli, 1980) 
Depending on which entity the authority is being transferred to, decentralization can be classified according to the following two dimensions. One dimension separates functional and areal decentralization. Functional decentralization occurs when authority to perform specific functions are transferred to smaller and more flexible specialized field agencies that are supposed to be closer to the end user. In case of fire protection, one can think of transferring authority to deal with specialized fire protection functions (for example, forest fires) from central headquarters to individual agencies. Areal decentralization refers to transferring responsibility for certain functions to organizations whose authority lies within well-defined spatial boundaries - a region, territory, district, county, municipality, etc.

Another dimension of decentralization distinguishes three degrees of decentralization: deconcentration, delegation and devolution. Deconcentration is the least extensive form of decentralization and involves transferring authority among different levels of the same government. Decentralization of this kind can be as limited as the shifting of workload from staff employed at central government agency headquarters which is located in the national capital of the country to staff employed in regional offices which are located around the country without transferring any decision making power in terms of how this workload is supposed to be performed. Deconcentration can be taken further by creating field administration, in which case a transfer of workloads from a central location to periphery is accompanied by the transfer of decisionmaking power to field staff, providing them with some flexibility to adjust the execution of central orders to local conditions as long as they stay within the guidelines set by the central agency. Under a system of field administration the transfer of decision making power is limited and field staff are employed by a central agency for the most part staying under its direct control.

A greater degree of decentralization is achieved by delegation, in which case decision-making authority to perform specific functions is transferred to organizations that stay only under the indirect control of central government agencies. In other words, while not being totally controlled by the central government, such organizations are ultimately accountable to it. Examples of such organizations include local governments, public corporations, regional planning and area development authorities, multi-purpose and single-purpose functional authorities, and project implementation units. Delegation implies the transfer of broader authority than deconcentration to implement decisions related to specific functions.

Devolution represents the most extensive form of decentralization as in this case authority to exercise particular functions goes to local entities that are not part of any command structure. Some authors argue that devolution is the only form of transferring decision-making powers that is consistent with the concept of decentralization and should not be confused with deconcentration which occurs when central government operations are decentralized (Martinez-Vazquez, Lago-Penas, \& Sacchi, 2017).

Following classification suggested earlier, we can outline four characteristics of devolution: 1) it requires that local government be given autonomy and independence and be clearly perceived of a separate level over which central authorities exercise little or no direct control; 2) the local units must have clear and legally recognized geographical boundaries over which they exercise authority and within which they perform public functions; 3) local governments must be given corporate status and the power to raise sufficient resources to perform specified functions; 4) devolution implies local governments are perceived of by local citizens as organizations providing services that satisfy their needs and as governmental units over which they have some influence. (Rondinelli, 1981)

Finally, there is market decentralization that may take the forms of privatization or deregulation in which case functions that had been provided by the government are transferred to businesses, community groups, cooperatives, private voluntary associations, and other non-government organizations (Decentralization Thematic Team, n.d.). Government can either contract out the provision of certain services to commercial enterprises while maintaining tight control over quantity and quality of those services or step aside and allow businesses to take over the provision of the services in accordance to the consumers' demand.

\section{Measuring Decentralization}

While theoretically and conceptually useful, the above definitions of decentralization are rather hard to apply when it comes to measuring the degree to which one of those types of decentralization are extended. 
As noted in earlier works regarding this topic, when looking for a good measure of decentralization one should focus on the following: locally raised own revenues, autonomy of expenditure decisions, locally spent national grants, and number and size of local units. (Martinez-Vazquez, Lago-Penas, \& Sacchi, 2017) However, applying these measures might not be as straightforward in practice: own revenues might be difficult to separate from assigned revenue sources which may over-state actual revenue autonomy and it is quite challenging to assess the degree to which centrally determined standards of service or laws issued by higher level tiers of legislature limit the local governments' autonomy in implementing their own policies. Given the imitations of available data, we rely on the average size of fire departments in each state to assess the degree of decentralization.

\section{Identifying Factors That Can Help Explain Fire Loss Differences Between Territories}

As decentralization of fire protection and prevention service is clearly not the only factor that affects fire safety outcomes, we need to take a look at the literature discussing such factors. Surprisingly, there is only one work of that kind that we are able to locate: Rardin and Mitzner study various hypotheses which have been advanced to explain fire loss differences among nations to understand why the United States was leading the industrialized world in fire loss in the 1970s (Rardin \& Mitzner, 1977).

Rardin and Mitzner go through a long list of various factors that are separated into three groups: 1) human factors, 2) the physical environment for fire, 3) fire protection communities and standards. One subgroup of human factors includes those related to economic and technological development: gross domestic product, national disposable income, and electrical energy consumption. Rardin \& Mitzner conclude that increased economic and technological development seem to be strongly associated with increased fire losses as they find positive correlation between monetary building fire loss and per capita national disposable income, between per capita building fires and electric energy consumption, and between per capita fire deaths and median educational level (Rardin \& Mitzner, 1977). However, they also find a negative correlation between per capita building fires and national disposable per capita income. Another subgroup of human factors discussed by Rardin and Mitzner are related to social and cultural patterns in society such as rates of crime, divorce, alcohol consumption, and population mobility (Rardin \& Mitzner, 1977). Rardin and Mitzner also discuss a phenomenon that they call the "frontier affluence" as a possible explanation of the US fire losses being higher than elsewhere (Rardin \& Mitzner, 1977). Their findings regarding the effect of the factors in this subgroup on fire safety outcomes are mostly inconclusive due to the lack of data. The only factor in the subgroup whose effect on fire safety outcomes they are able to assess is cigarette consumption per adult, which appears to be positively correlated with per capita fire deaths (Rardin \& Mitzner, 1977).

Rardin and Mitzner also suggest that the higher fire rates in the United States, Canada, and Australia could be attributed to predominantly dry, desert, and semi-arid steppe climate and cold, snowy climate in those countries that are conductive to fire as opposed to warm temperature, rainy climate which is presumably associated with low fire rates in nearly all of Western Europe and Japan. However, Rardin and Mitzner do not provide any data analysis to test those suggestions (Rardin \& Mitzner, 1977).

Finally, as Rardin and Mitzner discuss variations in the organization and functioning of the professional fire communities they notice that European and Japanese fire services appear to place greater emphasis on fire prevention as opposed to suppression than their counterparts in the United States (Rardin \& Mitzner, 1977). They further suggest that fire and building codes may be more strict outside the United States, the fire services tend to be organized more centrally, and the fire insurance industry is less influential in fire protection planning

While providing an insightful discussion, Rardin and Mitzner present their analysis in rather informal way as they rely on rather rudimentary data analysis by employing scatter plot diagrams. One of our goals in this work is to enhance previous work by creating a substantial data set and providing econometric analysis to determine the effect of relevant parameters on fire deaths in the US. 


\section{FIRE PROTECTION IN THE UNITED STATES}

The basic unit of fire protection in the US is a fire department - a public organization that provides fire prevention, fire suppression and associated emergency and non-emergency services to a jurisdiction such as a county, municipality, or organized fire district (Evarts \& Stein, 2020). It has been reported that in 2018 there were approximately 27,210 fire departments in the US and they employed approximately $1,115,000$ career and volunteer firefighters.

Fire protection is mostly provided at local level — both by local governments and private (mostly nonprofit) corporations (Fire \& Life Safety Policy Institute, 2018). In this regard there is little doubt that provision of this service in the US can be considered decentralized. However, it should also be taken into account that there is a certain level of coordination of fire protection around the country by means of federal agencies and various associations that contribute to fire protection throughout the nation. Such coordination efforts ought to produce some uniformity and to a certain extent result in an effect that is similar to centralization of fire protection services throughout the nation.

United States Fire Administration (USFA) is a federal agency that helps combat fires throughout the whole country by managing various federal programs aimed at assisting firefighting throughout the nation. The National Fire Protection Association (NFPA) is a nationwide association which develops, copyrights, and publishes consensus standards (codes) that are widely adopted in the United States. Despite its standards are not legal codes and have no statutory authority in their own right, they are written in such a way that facilitates their adoption into laws by appropriate government bodies. One of its numerous codes, NFPA 70, National Electrical Code, is in effect in all but 4 states in the US and as of 201844 states adopted a statewide electrical code (Fire \& Life Safety Policy Institute, 2018).

At state level in the US one should expect if not uniformity of fire protection services throughout the states, but at least adherence to some minimum standards as local fire protection fire service providers are supposed to comply with state laws issued by state legislatures and rules imposed by State Fire Marshal's Offices. Capturing the extent of such statewide regulations would definitely enhance our analysis of the effect of decentralization on fire safety outcomes, but at this point we find this task too challenging both in terms of conceptualization and data collection and leave it for further research.

Historically, states' involvement into the local fire protection affairs would take place in response to some disastrous events. For example, Indiana, Georgia, Pennsylvania, and Maine increased their involvement into fire protection service not long after and clearly under the influence of the Winecoff hotel fire in Atlanta in 1946. Indiana has passed its first statewide fire safety code and Georgia passed its building exit code, while Pennsylvania in 1947 and Maine in 1948 started requiring all firemen around the state to undergo formal training (Seck \& Evans, 2004).

Another disastrous event, 1904 Baltimore fire where 2500 buildings were destroyed, exposed a serious problem resulting from a lack of coordination as not all fire companies that arrived from eight surrounding cities and counties were able to use Baltimore hydrants as those did not fit the visiting firemen's hose couplings. Clearly, if these various fire brigades belonged to one large fire department, such a problem would not occur. However, one would think that even in a decentralized system such problems could be worked out through coordination and standardization, even if slowly. Indeed, following the Baltimore fire, a national standard for fire hydrant connections was adopted by the National Fire Protection Association. However, more than a century later after the problem was widely reported there are several different fire hose coupling standards in use in the U.S. today and as of 2014 only 18 out of the 48 most populated U.S. cities have installed national standard fire hydrants (Seck \& Evans, 2004).

While county, municipal, and township governments are in charge of fire protection most of the time, in many states there are other organizations that can be in charge of this service as well. Various fire districts, public corporations for firefighting and prevention, fire protection authorities, emergency service boards to name just a few types of such organizations are also in charge of fire protection throughout the U.S. Table 1 in Appendix provides information on various types of public governments involved into fire protection service provision throughout the U.S. 
Another dimension that adds variety to the way fire protection is provided in the US is that both public and private fire departments can be staffed by career or volunteer personnel. In 2018 out of total 29,705 fire departments in the United States 3,009 (10 percent) of departments were comprised solely of career firefighters, 19,122 (64 percent) were all volunteer, 2,368 (8 percent) were mostly career, and 5,206 (18 percent) were mostly volunteer (Evarts \& Stein, 2020).

Local governments usually establish their own fire departments, but it is also common for them to subsidize private fire departments instead. For example, in Tennessee out of the 730 fire departments, $354(48 \%)$ are privately operated and $311(43 \%)$ are public (Adelrazes, Corley, Lippard, \& RoehrichPatrick, 2013). It is important to keep in mind that both public and private fire departments must comply with state law and follow rules established by the State Fire Marshal's Office and that state laws usually establish minimum requirements for firefighters' training. While most private volunteer fire departments operate as nonprofit corporations there are examples of for-profit fire departments as well. For example, in Tennessee the largest for-profit fire department is Rural Metro, which operates in Knox County on a fee basis, providing service to residents of the Knoxville city limits and in certain industrial zones (Adelrazes, Corley, Lippard, \& Roehrich-Patrick, 2013). Also, it is common for private fire departments to enter into contracts with local governments to provide fire service. In such cases one could argue that private fire departments conceptually are not that different from public fire departments as they are supposed to provide their services under certain level of control from those local governments that hire them.

Fire departments in the US get their funding either from taxes, fees, government grants, or donations. Tax revenue could either come in the form of general fund revenue or in the form of property taxes earmarked for fire service. One quarter of all fire departments in the state got most of their revenue in donations (Adelrazes, Corley, Lippard, \& Roehrich-Patrick, 2013). The Assistance to Firefighters Grant (AFG) Program administered by the Federal Emergency Management Agency (FEMA) in 2016 distributed \$658 million among fire departments across the country through the Assistance to Firefighters Grant (AFG) Program and the Staffing for Adequate Fire and Emergency Response Firefighters (SAFER) program, which represented 1.37 percent of the amount spent by local governments on fire protection in that year (Kruger \& Gallagher, 2019).

\section{DATA}

Ideally, we would like to base our empirical analysis on detailed statistics of fire loss in the US like the ones provided by annual reports on fire loss in the United States that include number of fires, civilian fire deaths, civilian fire injuries, property loss, and intentionally set fires (Ahrens \& Evarts, 2020). Fire property loss would be a desirable parameter to focus on to maintain this work's economic focus. However, data for fire property loss are only reported for the US as a whole. This problem applies to a number of other statistics, and in general we have to deal with a tradeoff between availability of data and the scale of their disaggregation: while we would like to disaggregate the data as much as possible to obtain larger number of points of observation, there is a limit in how far "down" we can go in this process. Clearly, all the aggregated data initially were collected from individual units, and theoretically could be disaggregated back, but such disaggregation while theoretically possible is not achievable in practice, at least at this stage of our research. For example, the NFPA reports mentioned above refer to the data collected during the NFPA Survey of Fire Departments for US Fire Experience and the NFPA Fire Service Survey. However, in response to our inquiry regarding a possibility to access the raw data to identify individual fire departments and fire loss statistics related to the territories that they serve, we were informed by a NFPA

representative that none of the raw data from the NFPA surveys are shared, even if anonymized. Even if getting such data were possible, we should realize that to get the full advantage of that data would require matching it with socio-economic characteristics of the territories to be able to apply a multivariable statistical analysis to the data and obtaining socio-economic characteristics of the territories at that level of disaggregation is a challenge of its own. Possibly, such an endeavor could be achieved by limiting the scope of research to a smaller territory (for example, an individual state rather than the entire US), but in this work 
we focus our attention on analyzing data at state level and leave possible disaggregation of the data for future research.

\section{Description of the Data and the Results}

Given the above limitations with fire loss data, we use fire death rate per million population (201517) as a dependent variable in our regression model. This parameter's average is 13 fire deaths per million over the three years and it varies between states by more than sixfold from 4.6 in 2017 in New Jersey to 29.2 in 2017 in West Virginia. This parameter remains relatively stable over time and when averaging the data over the period of the three years New Jersey still stays at the bottom of the list with 5.7 and West Virginia stays on top of the list with 25.6. While there was a slight increase in the average across the states from 12 fire deaths per million in 2015 to 13 fire deaths per million in 2017, there is a significant variation in this parameter among individual states: the largest increase can be observed in West Virginia where the fire deaths per million doubled from 10 in 2015 to 19.4 in 2017 and the largest drop can be seen in Nebraska-from 15 in 2015 to 8.3 in 2017.

The number of registered fire departments vary from 1,794 in Pennsylvania to only 11 in Hawaii with the average of 544 fire departments per state. As the size of the states both in terms of their population and the area varies greatly, it makes sense to look at the number of people served on average by one fire department and the area per one fire department in each state. The largest number of people served on average by one fire department is 129,778 for Hawaii, with California being a distant second with 44,762 inhabitants per one fire department. North Dakota is at the bottom of the list with 2,349 people per one fire department on average. The average across the states is 14,420 people per one fire department.

There is also a large variation in square miles per one fire department between states as it goes from 3,635 in Alaska and 1,262 in Nevada to only 14 in Rhode Island and 10 in New Jersey with the average throughout all states of 251 square miles per one fire department.

Coefficients for both parameters have expected positive signs in our regression model, indicating that in those states where one fire department on average serves larger population and deals with larger territories, fire death rate tends to be larger. In reverse, it means that in those states where one fire department on average serves smaller population and deals with smaller territories, fire death rate tends to be smaller. These results are consistent with the hypothesis that decentralization tends to improve fire safety service delivery.

Population per county, which can be considered as an indirect measure of public service delivery in states varies from 13,076 people in South Dakota to 1,364,722 people per county in Massachusetts with the average of 158,907 people per county thought the nation. However, a coefficient for this variable in our regression model is not statistically significant.

Surprisingly, per capita local budgets fire protection expenditures which vary from 37 dollars per capita in Delaware to 402 dollars per capita in District of Columbia with the average of 141 dollars per capita, does not seem to produce any significant effect on fire death rate in the states. Possible explanation: private donations are not counted in fire protection expenditures. Also, endogeneity might be present as well if those states were the risk of fire is lower choose to spend less money, and vice versa.

There are two variables related to climate characteristics of the states that we include in our model: heating degree days ${ }^{1}$ and total yearly precipitations. Heating degree days are included into our regression model under the assumption that higher demand for energy need to heat a building is correlated to the more frequent and intensive use of heating devices which might increase the risk of fires. This parameter measures how cold the temperature was during a period of days. This variable goes from 11584 for Alaska to 23 for Hawaii, with the average of 5418. Its regression coefficient has the expected positive sign and is statistically significant.

Another climate related variable that one would expect to influence the risk of fires is the average total yearly participation across states. This variable goes from 63 inches in Hawaii and 60 inches in Louisiana to 12 inches in Utah and 10 inches in Nevada. Interestingly, while its regression coefficient is statistically significant it has unexpected negative sign, indicating that states with higher annual total yearly precipitation tend to have lower fire death rates. 
There is also a number of social-economic variables included in our analysis, some of which have the expected effect on the fire deaths across states and of which have not. Per capita total electricity retail sales vary from 28.9 MWh in Wyoming and 27.4 MWh in North Dakota to 6.5 MWh in Hawaii and California (seemingly surprising low per capita number for California is due in part to its mild climate and its energy efficiency programs), with the average of $13.3 \mathrm{MWh}$. This variable positively correlates with fire deaths throughout the sates, which is consistent with previous findings.

Median household income that varies from 82,604 dollars per year in District of Columbia and 81,868 in Maryland to 44,921 in West Virginia and 43,567 in Mississippi with the average of 60,621, predictably correlates negatively with fire deaths throughout states at a statistically significant level, which is consistent with the arguments presented by (Evans, 1990).

Neither educational attainment measured as percent of high school or higher varies from 93 in Montana to 83 in California with the average of 89 , nor educational attainment measured as percent of bachelors or higher seem to have any noticeable effect on fire death rates.

Out of those socio-economic factors that one would expect to be positively correlated with fire death rates only cigarette use among adults has the expected and statistically significant effect. Intensity of binge drinking ${ }^{2}$ among adults that varies from 8.3 drinks in Arkansas and 7.9 in West Virginia to 6.2 in District of Columbia and Washington with the average of 7.0 drinks has no effect on fire death rates according to our estimates. Neither do alcohol consumption measured in gallons per capita, nor annual unemployment rates.

Interestingly, prevalence of binge drinking ${ }^{3}$, which varies from $24.9 \%$ in North Dakota and $24.4 \%$ in Wisconsin and District of Columbia to $11.4 \%$ in Utah and $10.9 \%$ Tennessee with the average of $17.3 \%$, seem to be positively correlated with fire death rates according to an estimate of its coefficient in our regression model.

Summary of our empirical results are presented in Tables 1 and 2.

TABLE 1

SUMMARY OF OUR EMPIRICAL RESULTS

\begin{tabular}{|c|c|c|c|}
\hline Source & \multicolumn{2}{|l|}{ SS } & MS \\
\hline Model & 1023.46623 & 15 & 68.2310819 \\
\hline Residual & 239.140046 & 35 & 6.83257274 \\
\hline Total & 1262.60627 & 50 & 25.2521255 \\
\hline Number of obs & $=$ & 51 & \\
\hline $\mathrm{F}(15,35)$ & $=$ & 9.99 & \\
\hline Prob $>$ F & $=$ & 0.0000 & \\
\hline R-squared & $=$ & 0.8106 & \\
\hline Adj R-squared & $=$ & 0.7294 & \\
\hline Root MSE & $=$ & 2.6139 & \\
\hline
\end{tabular}




\section{TABLE 2}

SUMMARY OF OUR EMPIRICAL RESULTS

\begin{tabular}{l|llll}
\hline & Coef. & St. Error & $\mathrm{t}$ & $\mathrm{P}>|\mathrm{t}|$ \\
\hline Population per fire department & 0.0000507 & 0.000023 & $\mathbf{2 . 2 1}$ & 0.034 \\
Square miles per fire department & 0.0033774 & 0.0012464 & $\mathbf{2 . 7 1}$ & 0.01 \\
Population per county & $-2.45 \mathrm{E}-06$ & $2.33 \mathrm{E}-06$ & -1.05 & 0.299 \\
$\begin{array}{l}\text { Fire protection expenditure, per capita } \\
\text { Heating degree days }\end{array}$ & 0.0030632 & 0.0097659 & 0.31 & 0.756 \\
$\begin{array}{l}\text { Average total yearly precipitation for each } \\
\text { state }\end{array}$ & 0.0010569 & 0.0004424 & $\mathbf{2 . 3 9}$ & 0.022 \\
$\begin{array}{l}\text { Electricity retail sales, per capita, MWh } \\
\text { Median Household Income }\end{array}$ & 0.144645 & 0.0429064 & $\mathbf{3 . 3 7}$ & 0.002 \\
$\begin{array}{l}\text { Educational Attainment by State Percent } \\
\text { High School Or Higher }\end{array}$ & -0.290339 & 0.1188889 & $\mathbf{2 . 4 4}$ & 0.02 \\
$\begin{array}{l}\text { Educational Attainment by State Percent } \\
\text { Bachelors Or Higher }\end{array}$ & -0.2289594 & 0.3025965 & -0.76 & 0.454 \\
$\begin{array}{l}\text { Current Cigarette Use Among Adults } \\
\text { Prevalence of Binge Drinking, percent }\end{array}$ & 0.3694036 & 0.1951631 & 1.89 & 0.067 \\
$\begin{array}{l}\text { Intensity of Binge Drinking Among US } \\
\text { Adults }\end{array}$ & -0.4308999 & 0.1766059 & $\mathbf{- 2 . 4 4}$ & 0.02 \\
$\begin{array}{l}\text { Alcohol Consumption Gallons per capita } \\
\text { Average Annual Unemployment Rates by }\end{array}$ & -0.647696 & 1.540545 & 1.07 & 0.292 \\
$\begin{array}{l}\text { State } \\
\text { Const. }\end{array}$ & -0.8437142 & 0.871761 & -0.97 & 0.34 \\
\hline
\end{tabular}

\section{CONCLUSION}

There is a great variation in how centralized/decentralized fire protection services are around the world, both between countries and between jurisdictions within countries. Previous research that illustrates how decentralization benefits various branches of publicly provided services (for example, education and health) has encouraged us to study the effect of decentralization on fire protection service outcomes. We focus on fire death rates rather than fire property losses due to accessibility of data for this parameter. Another choice made in response to the availability of data is focusing on the United States rather than collecting data across countries throughout the world. While using data associated with local jurisdictions (counties or municipalities) as points of observation would allow us to increase the size of our data set and improve statistical inference of our results, collecting data at this level of disaggregation does not seem feasible at this point. Thus, we chose to use US states as points of observation as this choice provides us with the best balance between the number of observations and availability of data.

In the empirical section of our work we estimate the effect of various factors on fire death rates across the states, using the average size of fire departments across the states as a measure of decentralization in our OLS model. According to our estimates, a number of climate and socio-economic explanatory factors 
predictably affect fire death rates positively (for example, heating degree days, per capita electricity retail sales), some of those factors predictably affect fire death rates negatively (for example, median household income), while some do not seem to produce an expected effect (for example, fire protection expenditure per capita) or even show an unexpected effect (for example, prevalence of binge drinking).

Most importantly for the purpose of this work, the estimates show that the average size of fire departments measured both in population and in the area served by one fire department positively correlates with fire death rates, which we interpret as an evidence that decentralization is likely to improve the outcomes of fire protection services in those states where these services are more decentralized. While these results should be interpreted with caution, especially in view of possible endogeneity, they bring more light on the possible benefits that decentralization is capable of and open a new path for future research.

\section{ENDNOTES}

1. Heating degree days are a measure of how much (in degrees), and for how long (in days), the outside air temperature was below a certain level.

2. Binge drinking is defined as 4 or more drinks for a woman or 5 or more drinks for a man on an occasion during the past 30 days. Intensity is defined as the average largest number of drinks consumed by binge drinkers on any occasion in the past 30 days.

3. Prevalence of binge drinking is defined as percent of people ages 18 and older who reported that they engaged in binge drinking in the past month.

\section{REFERENCES}

Adelrazes, R., Corley, C., Lippard, C., \& Roehrich-Patrick, L. (2013). Fire Service in Tennessee. Nashville: Tennessee Advisory Commission on Intergovernmental Relations.

Ahrens, M., \& Evarts, B. (2020). Fire Loss in the United States During 2019. National Fire Protection Association.

Decentralization Thematic Team, W.B. (n.d.). What is Decentralization? Retrieved from $\mathrm{http}: / /$ www.ciesin.org/decentralization/English/General/Different_forms.html

Department of Administration and Information Economic Analysis Division. (2005). The Economic Impact of Fire Damage on Wyoming's Economy from a Business Perspective. Cheyenne.

Escaleras, M., \& Register, C. (2012). Fiscal decentralization and natural hazard risks. Public Choice, pp. $165-183$.

Evans, R.J. (1990). Economic growth and fires: the case of Japan. Keio Economic Studies, 27(1), 51-59.

Evarts, B., \& Stein, G.P. (2020). US Fire Department Profile 2018. National Fire Protectio Association (NFPA).

Faguet, J-P. (2004). Does decentralization increase government responsiveness to local needs? Evidence from Bolivia. Journal of Public Economics, pp. 867-893.

Faguet, J-P., \& Sanchez, F. (2014). Decentralization and access to social services in Colombia. Public Choice, pp. 227-249.

Falch, T., \& Fischer, J.A. (2012). Public sector decentralization and school performance: International evidence. Economic Letters, pp. 276-279.

Fire \& Life Safety Policy Institute. (2018). Falling Behind on Electrical Safety. NFPA.

Freinkman, L., \& Plekhanov, A. (2010). FISCAL DECENTRALIZATION AND THE QUALITY OF PUBLIC SERVICES IN RUSSIAN REGIONS. Public Finance and Management, pp. 117-168.

Habibi, N., Huang, C., Miranda, D., Murillo, V., Ranis, G., Sarkar, M., \& Stewart, F. (2003).

Decentralization and human development in Argentina. Journal of Human Development, pp. 73101.

Johnson, C., Lloyd-Williams, H., \& Edwards, R.T. (2016, August). The Case for Investing in Prevention: Fire Prevention. Retrieved June 2020, from https://cheme.bangor.ac.uk/documents/caseinvesting-fire-prevention.pdf 
Kruger, L.G., \& Gallagher, J.C. (2019). Assistance to Firefighters Program: Distribution of Fire Grant Funding. Congressional Research Service.

Litvack, J., Ahmad, J., \& Bird, R. (1998). Rethinking Decentralization in Developing Countries.

Washington, D.C.: The World Bank.

Martinez-Vazquez, J., Lago-Penas, S., \& Sacchi, A. (2017). THE IMPACT OF FISCAL

DECENTRALIZATION: A SURVEY. Journal of Economic Surveys, pp. 1095-1129.

Rardin, R.L., \& Mitzner, M. (1977). Determinants of international differences in reported fire loss. Gerogia Institute of Technology, Atlanta, Georgia.

Rondinelli, D. (1981). Government Decentralization in Comparative Perspective: Theory and Practice in Developing Countries. International Review of Administrative Sciences, pp. 133-145 .

Seck, M.D., \& Evans, D.D. (2004). Major U.S. Cities Using National Standard Fire Hydrants, One Century After the Great Baltimore Fire. Gaithersburg, MD: United States Department of Commerce, Technology Administration, National Institute of Standards and Technology.

U.S. Department of Commerce; U.S. Fire Administration; National Fire Data Center. (1978). Fire in the United States, Death Injuries, Dollar Loss, and Incidents at the National, State, and Local Levels.

Zhuang, J., Payyappalli, V.M., Behrendt, A., \& Lukasiewicz, K. (2017). Total Cost of Fire in the United States. University at Buffalo, Department of Industrial and Systems Engineering. Buffalo: Fire Protection Research Foundation.

\section{APPENDIX: TYPES OF PUBLIC GOVERNMENTS INVOLVED INTO FIRE PROTECTION SERVICE PROVISION IN THE U.S}

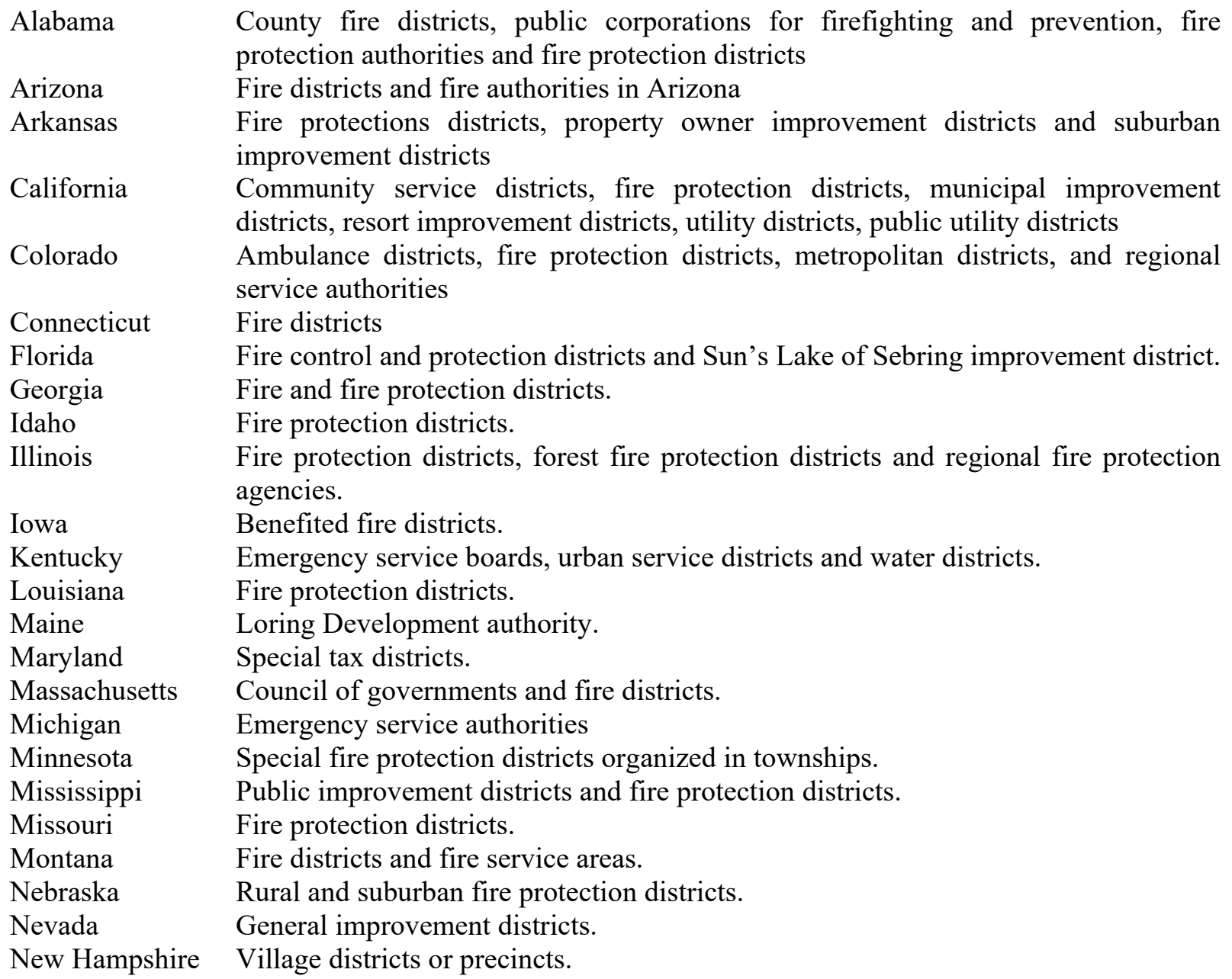


$\begin{array}{ll}\text { New Jersey } & \text { Fire districts. } \\ \text { New York } & \text { Joint fire districts and town fire districts. } \\ \text { North Carolina } & \text { County service districts. } \\ \text { North Dakota } & \text { Rural fire protection districts } \\ \text { Ohio } & \text { Joint fire districts and fire protection districts. } \\ \text { Pennsylvania } & \text { Fire districts in first-class townships } \\ \text { Rhode Island } & \text { Fire districts. } \\ \text { South Carolina } & \text { Fire districts. } \\ \text { South Dakota } & \text { Emergency fire districts, improvement districts, rural fire protection districts. } \\ \text { Tennessee } & \text { Utility districts. } \\ \text { Texas } & \text { Emergency fire districts, fire control and prevention districts, special utility districts. } \\ \text { Utah } & \text { Basic local districts, fire protection districts and local building authorities. } \\ \text { Vermont } & \text { Central Vermont Public Safety Authority and fire districts. } \\ \text { Virginia } & \text { Sanitary districts. } \\ \text { Washington } & \text { Fire protection districts. } \\ \text { West Virginia } & \text { County fire boards. } \\ \text { Wyoming } & \text { Fire protection districts. }\end{array}$ 